Universidade Tecnológica Federal do Paraná - UTFPR

Campus Ponta Grossa - Paraná - Brasil

ISSN: 1981-3686/ v. 08, n. 02: p. 1336-1347, 2014

D.O.I. $10.3895 / \mathrm{S} 1981-36862014000200004$
Revista Brasileira de Tecnologia

Agroindustrial

\title{
A SEGURANÇA DE ALIMENTOS NO CONTEXTO DO IDOSO
}

\section{FOOD SAFETY IN THE CONTEXT OF THE ELDERLY}

\author{
Paloma Antunes Blanc. ${ }^{1}$; Denise Rosane Perdomo Azeredo ${ }^{2}$ \\ ${ }^{1}$ Programa de Pós-Graduação Lato Sensu em Segurança Alimentar e Qualidade Nutricional, Instituto Federal \\ de Educação, Ciência e Tecnologia do Rio de Janeiro - IFRJ - Rio de Janeiro - palomaablanc@ @mail.com \\ ${ }^{2}$ Instituto Federal de Educação, Ciência e Tecnologia do Rio de Janeiro - IFRJ - Rio de Janeiro - \\ deniseperdomo@uol.com.br
}

\begin{abstract}
Resumo
A maior expectativa de vida da população somada às mudanças dos hábitos alimentares colabora para o aumento da incidência das doenças crônicas, e as modificações decorrentes do processo de envelhecimento resultam em alterações fisiológicas, tornando essa faixa da população mais susceptivel às doenças transmitidas por alimentos - DTA. O objetivo deste estudo foi avaliar o comportamento do consumidor no que diz respeito à segurança dos alimentos nos lares de idosos. Foi realizado um estudo descritivo, de caráter exploratório (aplicação de questionário), com 62 frequentadores habituais $(92 \%$ mulheres e $8 \%$ homens) de uma rede varejista de hortifrutigranjeiros localizada na zona sul da cidade do Rio de Janeiro. O critério utilizado foi amostragem de conveniência. De acordo com os dados coletados, observou-se que a principal responsável pelo preparo de refeições era a empregada doméstica (55\%). As doenças mais frequentes nos idosos foram hipertensão (42,4\%), doenças cardiovasculares (30,3\%), seguidos de diabetes $(18,2 \%)$ e câncer $(9,1 \%)$, caracterizando o perfil de vulnerabilidade às DTA. Os resultados demonstram o desconhecimento dos consumidores no tocante às suas responsabilidades na segurança de alimentos. Observaram-se práticas inadequadas em relação à conservação dos alimentos em temperaturas de refrigeração e congelamento. Quarenta e dois por cento dos consumidores afirmaram descongelar alimentos à temperatura ambiente. Outras práticas relatadas pelos consumidores demonstraram a possibilidade de contaminação cruzada no ambiente doméstico. É necessário informar sobre as práticas preventivas com recursos e métodos apropriados para auxiliar os idosos a relacionar as falhas de segurança alimentar cometidas nas cozinhas de suas residências por eles próprios ou terceiros.
\end{abstract}

Palavras-chave: idosos; segurança de alimentos; cozinha doméstica.

\section{Introdução}

No Brasil, é considerado idoso aquele que tenha atingido idade de 60 anos, de acordo com a legislação específica do Ministério da Previdência e Assistência Social (Lei no 8.842, de 4 de janeiro de 1994 e Decreto ${ }^{\circ} 1.948$, de 3 de junho de 1996). 
Com a transição demográfica, ocorreu uma mudança brusca nas taxas de fecundidade e mortalidade, havendo diminuição drástica desses indicadores. A transição epidemiológica, definida pelo declínio das doenças infecto- parasitárias e aumento das doenças crônicas não transmissíveis, também é responsável pelo envelhecimento da população. O Brasil possui pouco mais de 23 milhões de pessoas com 60 anos ou mais (IBGE, 2012), com projeções de crescimento desse grupo populacional para 39 milhões até 2030 e 63 milhões até 2050 (IBGE, 2008).

A maior expectativa de vida da população somada às mudanças dos hábitos alimentares, do aumento do sedentarismo e do estresse, colabora para o aumento da incidência das doenças crônicas, que hoje constituem um sério problema de saúde pública. Doenças cardiovasculares, câncer, diabetes e doenças respiratórias são as maiores responsáveis pela mortalidade no mundo. No Brasil, nas últimas décadas, as doenças crônicas não transmissíveis tornaram-se as principais causas de óbito e de incapacidade prematura (SILVA e CATÃO, 2012).

Durante o processo de envelhecimento vários fatores contribuem para o aumento a susceptibilidade às doenças transmitidas por alimentos - DTA. Nesta fase da vida, o aparelho digestivo funciona mais lentamente, ocorrendo menor produção de ácido gástrico e diminuição da motilidade intestinal, e desse modo, o paladar e o olfato podem sofrer alterações. O uso habitual de medicamentos também pode ter efeitos secundários e o próprio mecanismo de ação da doença crônica pode enfraquecer o sistema imunológico, deixando o indivíduo mais exposto aos patógenos causadores de DTA. O uso excessivo de antibióticos também pode influenciar essa condição. Os idosos correm sérios riscos ao contraírem DTA pelo fato de não conseguirem se recuperar como os indivíduos mais jovens, podendo passar por internação hospitalar, ou dependendo da gravidade até mesmo correrem risco de morte. Para evitar contrair uma doença de origem alimentar, os idosos, cuidadores e familiares devem ser exigentes ao manusear, preparar e consumir alimentos (SMITH, 1998; LEITE e WAISSMANN, 2006; FDA, 2011).

Nos Estados Unidos e em alguns países da Europa, a maioria dos casos e pequenos surtos de intoxicação alimentar são decorrentes da falta de conhecimento e/ou prática de hábitos de higiene e segurança dos alimentos nos lares (WORSFOLD e GRIFFITH, 1997). O conceito de qualidade dos alimentos é construído em função da dinâmica da relação de consumo e envolve o Estado, o setor produtivo e os consumidores. No Brasil, não se tem base de dados para afirmar que parte da ocorrência de doenças transmitidas por alimentos ocorre por causa da negligência do consumidor, às vezes por desconhecimento, outras vezes por não aplicação das informações (PERETTI et al., 2010).

Muitos consumidores acreditam que o lar não é uma fonte de contaminação iminente, e a responsabilidade recai sobre a indústria e o comércio de alimentos. Além disso, poucos pequenos 
surtos são relatados aos órgãos responsáveis, dificultando o controle e fidedignidade dos dados existentes (WORSFOLD e GRIFFITH, 1997).

Os alimentos contaminados aparentemente são normais, apresentam odor e sabor normais e, como o consumidor não está devidamente esclarecido ou consciente dos perigos envolvidos, não consegue identificar qual alimento pode estar contaminado e porque ficou impróprio para consumo (AMSON et al., 2006).

As práticas inadequadas de processamento e higiene contribuem para a contaminação cruzada de alimentos, oferecendo riscos à saúde do manipulador de alimentos e de todos ao seu redor. O termo manipulador de alimentos é aplicado a todas as pessoas que podem entrar em contato com um produto comestível ou parte do mesmo em qualquer etapa da produção, ou seja, do campo a mesa do consumidor (CASTRO et al., 2011). Logo, o consumidor tem sua parcela de responsabilidade a partir da compra do alimento, pois, rotineiramente transporta, armazena, prepara, cozinha e realiza a refeição em sua casa.

A partir dessas considerações, o objetivo do presente estudo foi avaliar o comportamento do consumidor no que diz respeito à segurança dos alimentos nos lares de pessoas idosas.

\section{Material e Métodos}

Foi realizado um estudo descritivo, de caráter exploratório, através da aplicação de um questionário, com 62 frequentadores habituais (92,0\% mulheres e 8,0\% homens) de uma rede varejista de hortifrutigranjeiros localizada na zona sul da cidade do Rio de Janeiro. O critério de amostragem utilizado foi a amostragem de conveniência. Esse método de análise é uma prática normal em estudos qualitativos, quando o objetivo da pesquisa é obter uma estimativa grosseira de resultados relacionados a um sujeito ou tema, e envolve participantes disponíveis que atendem a critérios específicos - idosos, familiares de idosos ou empregada doméstica (CARRILLO et al., 2012). A participação dos entrevistados ocorreu de forma voluntária e os mesmos foram escolhidos aleatoriamente. A coleta de dados foi realizada por uma nutricionista. O grupo dos respondentes se caracterizou por idosos, empregadas domésticas ou familiares residentes no mesmo domicílio. O objetivo da entrevista foi investigar o comportamento do grupo no tocante à segurança de alimentos, dada a sua maior vulnerabilidade. Baseando-se nos critérios preconizados pelo FDA Food and Drug Administration (2011) para a segurança de alimentos, as perguntas foram separadas em grupos que abordavam questões sobre lavar, separar, cozinhar e refrigerar os alimentos. Os itens abordados no questionário podem ser observados na Figura 1. 
Figura 1 - Itens abordados no questionário

\section{Perguntas}

1 Quanto tempo os alimentos refrigerados ficam no carrinho até passarem pelo caixa?

2 Utiliza ou não bolsa térmica para transporte de alimentos refrigerados do supermercado para casa?

3 Utiliza algum meio de transporte do supermercado para casa?

4 Quanto tempo leva do supermercado até chegar em casa?

5 Qual a temperatura de armazenamento de alimentos refrigerados?

6 Em qual prateleira da geladeira esta temperatura é atingida?

7 Como descongela os alimentos?

8 Onde armazena os ovos?

9 Costuma ou não lavar as mãos no decorrer da manipulação de alimentos?

10 Qual produto utiliza para higienizar as mãos?

11 Com que material seca as mãos após à lavagem?

12 Com que frequência higieniza a superfície de trabalho no decorrer do preparo?

13 Qual produto utiliza para higienizar a superfície de trabalho?

14 A esponja utilizada para lavar a louça e a superfície de trabalho é a mesma?

15 Qual produto utiliza para higienizar vegetais?

16 Reutiliza ou não embalagens provenientes de alimentos crus para acondicionar outros tipos de alimentos?

17 Utiliza tábuas de corte separadamente para alimentos crus, cozidos e vegetais?

18 De qual material sua tábua de corte é composta?

19 Utiliza ou não os mesmos utensílios para manipular alimentos crus e cozidos?

20 Em qual recipiente armazena as sobras dos alimentos prontos para consumo?

21 Deixa ou não os alimentos prontos para consumo sob o fogão por mais de 90 minutos?

22 Se sim, porque adota esse procedimento?

23 Reaquece ou não as sobras mais de uma vez?

24 Reaquece as sobras no fogão, forno ou forno micro-ondas?

25 Para você, o governo informa e orienta o consumidor a respeito das boas práticas na manipulação de alimentos nos lares?

Você ou alguém de sua família/residência que trabalha enquadra(m)-se nos seguintes grupos?

a) Diabéticos ou pessoas apresentando disfunções ou doenças renais;

b) Doenças cardiovasculres;

c) Hipertensos;

d) Câncer.

\section{Resultados e discussão}

De acordo com os dados coletados, observou-se que a responsável pelo preparo de refeições, na maioria dos lares, era a empregada doméstica $(55,0 \%)$. As doenças mais frequentes nos idosos foram hipertensão $(42,4 \%)$ e doenças cardiovasculares (30,3\%), seguido de diabetes $(18,2 \%)$ e câncer $(9,1 \%)$, caracterizando os entrevistados com um perfil de vulnerabilidade as DTA. Sabe-se que os idosos vivem no estado conhecido como "imunossenescência", que se refere à existência de disfunções do sistema imune relacionados à idade e que resultam no aumento do risco de infecções. $\mathrm{O}$ uso indiscriminado de antibióticos e as deficiências nutricionais também contribuem para esse 
estado (GAVAZZI e KRAUSE, 2002; LEITE e WAISSMANN, 2006). As infecções mais frequentes na população geriátrica são pneumonia, as infecções do trato urinário e as infecções gastrintestinais (YAMAYA et al., 2001; NICOLLE, 2002; KLONTZ et al., 1997). Há evidências ainda, de que ocorrem altas taxas de mortalidade em surtos causados por Escherichia coli O157:H7 e por Campylobacter jejuni (CARTER et al., 1987; PREVOTS e SUTTER, 1997). Estes surtos podem ser explicados pelas alterações fisiológicas do trato gastrintestinal dos idosos, resultando em hipocloridria e diminuição da motilidade intestinal. Nesta situação, o estômago não consegue atuar como barreira protetora à entrada de enteropatógenos e o intestino não consegue remover os microorganismos patogênicos no decorrer da infecção (SMITH, 1998; LEITE e WEISMANN, 2006).

Os dados coletados demonstram o desconhecimento dos consumidores no tocante as suas responsabilidades na área de segurança de alimentos. Ao serem questionados se o governo informa e orienta o consumidor a respeito das boas práticas de manipulação de alimentos nos lares, 95\% dos entrevistados responderam negativamente. A incidência das práticas inadequadas de higiene, relatada pelos entrevistados encontra-se resumida na tabela 1.

Tabela 1- Práticas inadequadas de higiene relatadas pelos consumidores

\begin{tabular}{cc}
\hline Práticas inadequadas & Percentual (\%) \\
\hline Não usam bolsa térmica para transporte do alimento do supermercado para a residência. & 94,0 \\
Descongelamento do alimento a temperatura ambiente em bancadas. & 42,0 \\
Secagem das mãos com pano de prato. & 87,0 \\
Utilização da mesma esponja para lavar os pratos e higienizar as superfícies. & 69,0 \\
Não utilização de sanificantes para higienização dos vegetais. & 29,0 \\
Utilização tábuas de corte de madeira. & 42,0 \\
Utilização da mesma tábua para corte de alimentos crus e cozidos. & 76,0 \\
Utilização dos mesmos utensílios para manipular alimentos crus e cozidos. & 57,0 \\
\hline
\end{tabular}

\section{Transporte e estocagem do alimento}

Através do relato dos entrevistados sobre o transporte de alimentos refrigerados, pôde-se inferir que os alimentos adquiridos no ponto de venda ficam geralmente cerca de $1 \mathrm{~h}$ fora de refrigeração (gráfico 1). As mudanças bruscas de temperatura alteram a microbiota normal do alimento, possibilitando o aumento da carga microbiana do mesmo. Além de acelerar a deterioração, aumenta a multiplicação de micro-organismos patogênicos quando presentes, elevando as chances de uma contaminação (ANVISA, 2009). Outro ponto interessante, é que 50\% dos respondentes afirmaram que a temperatura de armazenamento dos alimentos refrigerados é entre $5^{\circ} \mathrm{C}$ e $10^{\circ} \mathrm{C}$, porém desconhecem que as geladeiras domésticas atingem temperaturas superiores as relatadas. O descongelamento de alimentos não deve ser feito à temperatura ambiente, pois este procedimento deve ser efetuado em condições de refrigeração à temperatura inferior a $5^{\circ} \mathrm{C}$ ou em forno de micro-ondas quando o alimento for submetido imediatamente ao cozimento (ANVISA, 2009). 
Gráfico 1 - Transporte dos alimentos adquiridos no ponto de venda até a residência dos consumidores

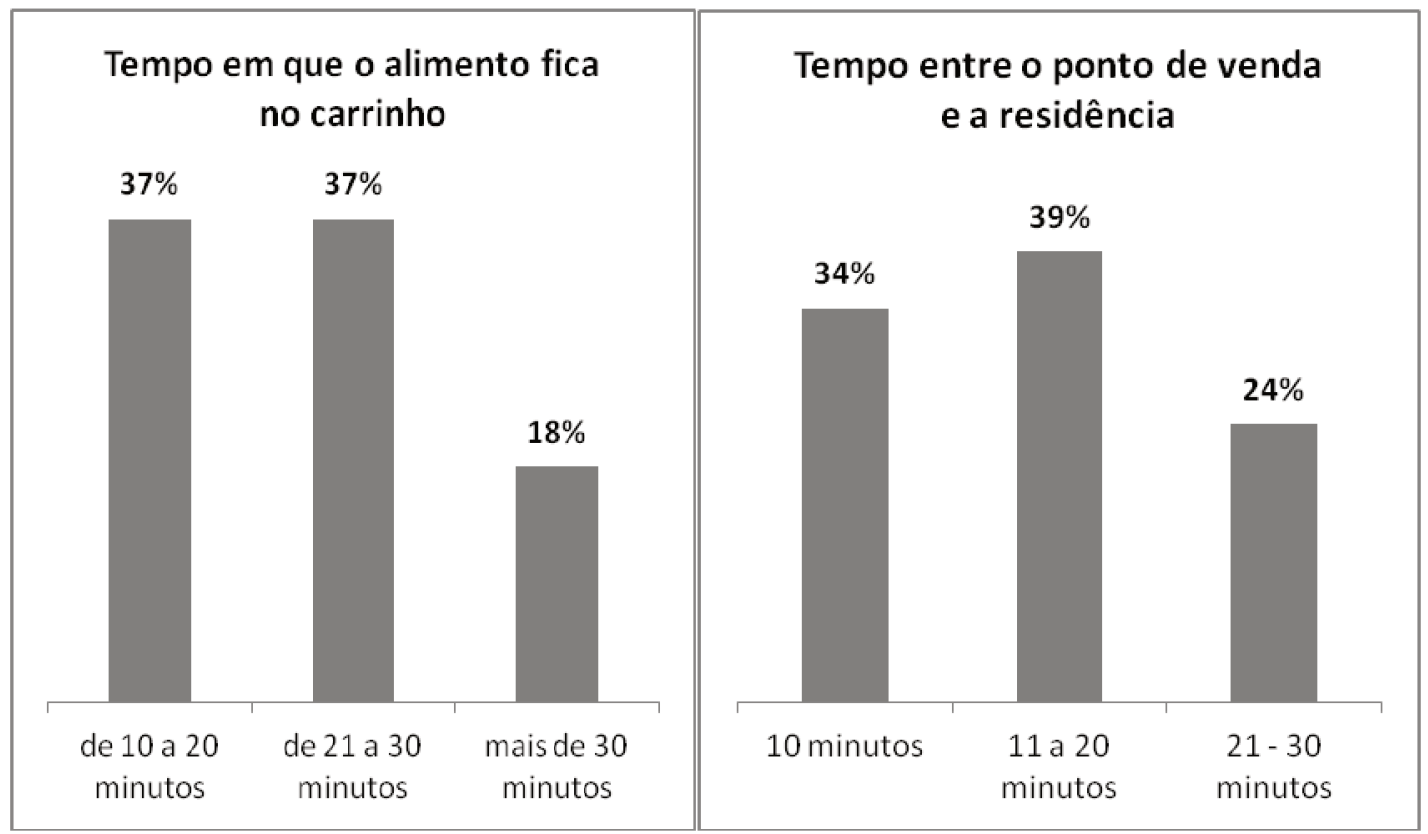

O tempo de exposição e manipulação de produtos perecíveis em temperatura ambiente também não deve exceder a 30 minutos, e 2 horas em área climatizada entre $12^{\circ} \mathrm{C}$ e $18^{\circ} \mathrm{C}$ (ANVISA, 2004; SENAC, 2001).

\section{Manuseio e preparo do alimento}

Sobre o hábito de higienizar as mãos ao longo do processo de manipulação de alimentos, 94,0\% dos entrevistados afirmaram realizar essa prática, e 66,0\% deles utilizam detergente neutro durante a lavagem das mãos. Segundo Xavier (2009), uma das principais não conformidades encontradas nos lares era a falta de higiene das mãos de donas de casa pertencentes às classes econômicas A, B e C. As donas de casa da classe econômica A tinham o hábito de manter contato com animais de estimação durante a manipulação, enquanto que as donas de casa da classe C realizavam a higienização ambiental ao mesmo tempo em que a manipulação de alimentos. O uso de detergente neutro para higienização das mãos também é inadequado, pois o mesmo é potencialmente incapaz de eliminar muitos dos micro-organismos que podem ser transmitidos das mãos do homem para os alimentos, sendo o sabonete bactericida inodoro o produto correto nesse processo (SOUNIS, 1995).

Os panos de prato são iminentes veículos de contaminação por permanecerem úmidos, e devem ser trocados e higienizados diariamente (BRASIL, 2005; ETCHEPARE et al., 2011). Os utensílios devem secar naturalmente, entretanto, caso seja necessário a utilização de panos de prato, eles devem estar adequadamente higienizados. A higienização dos panos de prato deve ser feita 
através de fervura em água por 15 minutos ou imersão em solução clorada por 10 minutos (uma colher de sopa por litro de água) (ETCHEPARE et al., 2011).

Observou-se que $42,0 \%$ dos entrevistados higieniza a superfície de trabalho em todas as etapas da manipulação e preparo de alimentos (antes, durante e após), e que 40,0\% higieniza somente após o preparo, o que aumenta as chances de contaminação cruzada. O produto mais utilizado pelos entrevistados na higienização das superfícies foi o detergente neutro, seguido do desengordurante. Somente 11,0\% utiliza água sanitária diluída em água (solução clorada). Para higienizar corretamente pias e bancadas, deve-se enxaguá-las em uma solução de uma colher de sopa de água sanitária sem perfume a $2 \%$ por litro de água, assim como para higienizar panos de prato, tábuas de corte e outros utensílios (FDA, 2011; MESA BRASIL SESC, 2003). Cabe citar que resíduos de mercúrio podem ser encontrados nas águas sanitárias, devido ao seu modo de obtenção (ZENEBON et al., 1994) sendo mais adequado o uso de soluções comerciais diluídas de hipoclorito de sódio a 10\% (ANDRADE e MACÊDO, 2004).

Merece destaque o dado da pesquisa que apontou a utilização da mesma esponja de limpeza para lavagem da louça e higienização de superfícies. As esponjas de limpeza entram diretamente em contato com utensílios e equipamentos que participam efetivamente da elaboração de refeições, constituindo grande fonte de contaminação por veicularem patógenos causadores de toxinfecções alimentares (ANDRADE, 2008). Estudos apresentam dados sobre a contaminação bacteriana por coliformes totais, coliformes fecais, bolores e leveduras (PUREZA, 2012; ENRIQUEZ et al., 1997; FRANCO e LANDGRAF, 2000). Os riscos de contaminação podem ser reduzidos se for realizada a desinfecção das esponjas por $100^{\circ} \mathrm{C}$ durante 4 minutos (PUREZA, 2012). Esse método é barato, fácil e rápido de ser realizado, e por isso deve ser amplamente divulgado entre os consumidores.

Sobre a higienização de vegetais, sabe-se que a sanificação de vegetais é um procedimento que visa diminuir a ocorrência de DTA (MEYER, 1994). No presente estudo, foram apontados como agentes sanificantes utilizados para higienização de vegetais, compostos à base de cloro (solução comercial de hipoclorito de sódio), água sanitária e vinagre. Observa-se que o percentual de indivíduos que não utiliza qualquer produto para higienizar vegetais nos lares de pessoas idosas é considerável. Essa atitude dentre muitas outras, pode vir a piorar o estado nutricional desses idosos devido à exposição a inúmeros micro-organismos patogênicos e protozoários presentes em hortaliças e frutas não higienizadas, dentre eles: Salmonella sp, Escherichia coli enteropatogênica, Entamoeba coli, Giardia sp, Toxocara sp, Taenia sp, Ascaris sp, Strongyloides sp, Trichuris sp (PALÚ et al., 2002; PAULA et al., 2003; NASCIMENTO et al., 2005; SANTOS e BIONDI, 2009). 


\section{Contaminação cruzada}

De acordo com a RDC 216 (2004), medidas devem ser adotadas com a finalidade de minimizar ao máximo esse risco como o contato direto ou indireto entre alimentos crus, semipreparados e prontos para o consumo, e os indivíduos que manipulam alimentos crus devem realizar a lavagem e a sanificação das mãos antes de manusear alimentos preparados. As principais práticas relativas a contaminação cruzada constatadas no estudo referem-se reutilização de embalagens provenientes de alimentos crus, tais como bandejas de carne, para acondicionar outros alimentos após lavarem as mesmas; utilização da mesma tábua de corte para diferentes alimentos e uso da tábua de material de madeira e plástico. Tal fato demonstra que o desconhecimento a respeito das tábuas de vidro. Estas últimas são as mais indicadas, pelo fato de não transmitirem substâncias tóxicas, odores, sabores, e também porque sua superfície é lisa e isenta de rugosidades, frestas e outras imperfeições que possam vir a comprometer a higiene das superfícies e alimentos (ETCHEPARE et al., 2011). As tábuas de corte de madeira e plástico são uma das principais responsáveis pela contaminação cruzada, pois é utilizada para cortes de diversos alimentos como carne crua, legumes, verduras, bem como alimentos prontos, encontrando as bactérias facilidade para migrarem e se disseminarem para os alimentos (FIGUEIREDO, 2002; MARTINS, 2003). Deve-se evitar o uso de madeira e de outros materiais que não possam ser limpos e sanitizados adequadamente.

\section{Cozimento do alimento}

Quando questionados sobre o reaquecimento das sobras, 73,0\% afirmaram reaquecê-las mais de uma vez e desse total, 66,0\% reaquecem no forno de micro-ondas. Sabe-se que o binômio tempo/temperatura é determinante na qualidade do produto final, principalmente pela qualidade microbiológica do alimento (MAZETO e MANEIRA, 2010). O tratamento térmico deve garantir que todas as partes do alimento atinjam a temperatura de, no mínimo, $70^{\circ} \mathrm{C}$. Temperaturas inferiores podem ser utilizadas no tratamento térmico desde que as combinações de tempo e temperatura sejam suficientes para assegurar a qualidade higiênico-sanitária dos alimentos (ANVISA, 2004). O forno de micro-ondas é o equipamento mais utilizado para reaquecer alimentos de acordo com os dados apresentados. Sobre a segurança e eficácia deste equipamento, ele pode não reaquecer os alimentos uniformemente, permitindo zonas frias onde as bactérias patogênicas podem sobreviver. Devido a isso, deve-se assegurar que os alimentos cozidos e/ou reaquecidos no forno microondas foram integralmente submetidos a uma temperatura segura utilizando termômetro para verificar se a temperatura de $70^{\circ} \mathrm{C}$ foi atingida. $\mathrm{O}$ alimento só deve ser consumido se essa temperatura interna mínima de segurança for alcançada. Deve-se lembrar que algumas embalagens de plástico liberam substâncias químicas tóxicas durante o aquecimento e não devem ser utilizadas no microondas para cozinhar ou reaquecer os alimentos (OMS, 2006). 


\title{
Acondicionamento do alimento pós-cozimento
}

Após o preparo, 94,0\% dos entrevistados deixam os alimentos prontos para consumo sob o fogão por mais de 90 minutos. Essa atitude é justificada de várias formas: 45,0\% seguem essa opção por hábito, 27,0\% por entenderem que o alimento quente pode danificar o refrigerador e 15,0\% por acreditarem não haver nenhum tipo de risco. Um dos guias de segurança alimentar elaborados pelo MAFF (Ministry of Agriculture, Fisheries and Food, 1991), aconselha a população a aquecer os alimentos apenas uma vez e só consumir quando estiver bem quente. Caso as bactérias sobrevivam à cocção, se não houver refrigeração pós-cocção adequada ou o armazenamento prolongado em temperatura ambiente, os mciro-organismos tem grande possibilidade de vir a causar um caso ou um surto, dependendo do número de pessoas atingidas (WORSFOLD e GRIFFITH, 1997).

\section{Considerações finais}

O desconhecimento das práticas de segurança dos alimentos por parte dos consumidores ficou evidente na maioria das questões analisadas. Uma das maneiras que pode vir a garantir a qualidade higiênico-sanitária dos alimentos é a orientação do consumidor através de programas educativos elaborados pelo governo e também pela iniciativa privada. É necessário informar sobre as práticas preventivas com recursos e métodos apropriados para auxiliar os idosos a relacionar as falhas de segurança de alimentos cometidas nas cozinhas de suas residências por eles próprios ou terceiros, com seu estado geral de saúde.

Práticas fundamentais para manutenção da segurança dos alimentos, como a manipulação adequada de alimentos e a conservação e consumo de alimentos de risco, podem ser orientados por profissionais capacitados das unidades básicas de saúde no atendimento dietético ambulatorial.

\begin{abstract}
The longer life expectancy of the population coupled with changes in eating habits contributes to the increased incidence of chronic diseases, and changes resulting from the aging process results in physiological changes, making this population group most susceptible to foodborne illness - DTA. The aim of this study was to evaluate consumer behavior with respect to food safety in nursing homes. We conducted a descriptive, exploratory (questionnaires), with 62 regulars (92\% women and $8 \%$ men) from a retailer of fresh produce located in the south of the city of Rio de Janeiro. The criterion used was a convenience sample. According to the data collected, it was observed that the primary responsibility for preparing meals was the maid (55\%). The most frequent diseases in the elderly were hypertension $(42.4 \%)$, cardiovascular disease $(30.3 \%)$, followed by diabetes $(18.2 \%)$ and cancer $(9.1 \%)$, characterizing the profile of vulnerability to DTA. The results demonstrate the ignorance of consumers with respect to their responsibilities in food safety. There were inadequate practices in relation to food preservation in refrigeration and freezing temperatures. Forty-two percent of consumers said defrost food at room temperature. Other practices reported by consumers demonstrated the possibility of cross-contamination in the home environment. You must report the preventive practices with appropriate methods and resources to assist the elderly relate to food safety flaws committed in the kitchens of their homes by themselves or others.
\end{abstract}

Key words: elderly; food safety; domestic kitchen 


\section{Referências}

ABREU, S. C.; CABRAL, M. M. W. Análises microbiológicas de placas de corte de madeira para identificação de bactérias pertencentes ao grupo das Enterobacteriaceae. Revista Científica da Universidade de Franca, Franca (SP) v. 5, n. $1 / 6$ jan. 2003 / dez. 2005.

ANDRADE, N.J. de.; MACÊDO, J.A.B. de. Higienização na Indústria de Alimentos. São Paulo: Editora Varela, 2004.

AMSON, G. V.; HARACEMIV, S. M. C.; MASSON, M. L. Levantamento de dados epidemiológicos relativos a surtos de doenças transmitidas por alimentos (DTAs) no estado do Paraná - Brasil, no período de 1978 a 2000 . Ciência e Agrotecnologia, Lavras, v. 30, n. 6, p. 1139-1145, 2006.

ANDRADE, N. J. Higiene na Indústria de Alimentos. Avaliação E Controle Da Adesão e Formação de Biofilmes Bacterianos. São Paulo: Editora Varela, 2008.

BRASIL. ANVISA - Agência Nacional de Vigilância Sanitária. RDC nº 216, de 15 de setembro de 2004. Dispõe sobre regulamento técnico de boas práticas para serviços de alimentação. Brasília, DF. Diário Oficial da União, D.O.U. de 16 $\begin{array}{llllll}\text { de setembro } & \text { de } & \text { Disponivel } & \text { file:///E:/Leis/03- }\end{array}$ $\% 20$ Obtida\%20no\%20curso\%20de\%20BPF/RDC\%20216.htm>. Acesso em 04 out. 2012.

BRASIL. ANVISA - Agência Nacional de Vigilância Sanitária. Temperatura e higiene garantem segurança dos alimentos. Disponível em: <http://www.anvisa.gov.br/divulga/noticias/2009/141009.htm>. Acesso em 02 out. 2012.

BRASIL. Ministério da Previdência e Assistência Social. Lei no 8.842, de 4 de janeiro de 1994 e Decreto nº 1.948 , de 3 de junho de 1996. Política Nacional do Idoso. $2^{\text {a }}$ ed. Brasília, DF, 1998. Disponível em: < http://www010.dataprev.gov.br/sislex/paginas/42/1994/8842.htm>. Acesso em 10 jul. 2012.

BRASIL. Ministério da Saúde. Secretaria de Atenção à Saúde. Coordenação-Geral da Política de Alimentação e Nutrição. Guia alimentar para a população brasileira; promovendo a alimentação saudável. Serie $\mathrm{A}$, 236p, Brasília, 2005. Disponível em: < http://dtr2001.saude.gov.br/editora/produtos/livros/pdf/05_1109_M.pdf>. Acesso em 10 jul. 2012.

CARRILLO, E.; VARELA, P.; FISZMAN, S. Influence of nutritional knowledge on the use and interpretation of Spanish nutritional food labels. Journal of Food Science, Vol. 71, Nr. 1, 2012.

CARTER A.O.; BORCZYK A. A.; CARLSON J.A.; HARVEY B.; HOCKIN J. C.; KARMALI M. A., et al. A severe outbreak of Escherichia coli 0157:H7 associated hemorrhagic colitis in a nursing home. The New English Journal of Medicine, 317(24): 1496-500, 1987. http://dx.doi.org/10.1056/NEJM198712103172403

CASTRO, F. T.; BARBOSA, C. G.; TABAI, K. T. Perfil de Manipuladores de Alimentos e a Ótica desses profissionais sobre alimento seguro no Rio de Janeiro (RJ). Oikos: Revista Brasileira de Economia Doméstica, Viçosa, v. 22, n.1, p.164-170, 2011.

ENRIQUEZ, C.E.; ENRIQUEZ-GORDILLO, R.; KENNEDY, D.I.; GERBA, C.P. Bacteriological survey of used cellulose sponges and cotton dishcloths from domestic kitchens. Dairy Food Environnemnt Sanitary, v. 17, n. 1, p. 20-4, 1997.

ETCHEPARE, M. A.; DEON, B. C.; HECKTHEUER, L. H.; SACCOL, S. Avaliação das boas práticas de higiene de esponjas, panos de prato e tábuas de corte no controle de doenças transmitidas por alimentos (DTAs) no município de Santa Maria - RS. Trabalho apresentado originalmente no I Congresso de Ciência e Tecnologia da UTFPR Campus Dois Vizinhos, 2011.

FIGUEIREDO, R. M. DVAs: guia prático para evitar DVAs - Doenças veiculadas por alimentos e recomendações seguras dos alimentos. São Paulo: Manole, 2002.

FRANCO, B. D. G. M.; LANDGRAF, M. Microbiologia dos alimentos. São Paulo: Atheneu, 2000.

GAVAZZI G.; KRAUSE K.H. Ageing and infection, The Lancet Infectious Diseases, v. 2, n. 11, p. 659-66, 2002. http://dx.doi.org/10.1016/S1473-3099(02)00437-1

IBGE. Censo Demográfico 2000: resultados do universo. Rio de Janeiro, 2000. Disponível em: <http://www.ibge.gov.br/ home/estatistica/população/censo 2000>. Acesso em 10 jul. 2012. 
IBGE. Projeção da população do Brasil por sexo e idade - 1980-2050. Revisão 2008. Disponível em: <http://www.ibge.gov.br/home/estatistica/populacao/projecao_da_populacao/2008/projecao.pdf>. Acesso em 11 jul. 2012.

KLONTZ K.C.; ADLER W.H.; POTTER M. Age-dependent resistence factors in the pathogenesis of foodborne infectious diseases. Aging, v. 9, n. 5, p. 320-6, 1997.

LEITE, L. H. M., WAISSMANN, W. Doenças transmitidas por alimentos na população idosa: riscos e prevenção. Revista de Ciências Médicas, Campinas, v. 15, n. 5, p. 369-377, 2006.

MARTINS, R.F. Higiene dos alimentos. Disponível em: <http://www.amure.com.br/higiene/higiene 004.php>. Acesso em 07 mai. 2012.

MAZETO, N. M. S.; MANEIRA, A. A. M. Tempo de armazenamento de alimentos prontos para consumo segundo RDC 216: revisão de literatura. 2010.

MESA BRASIL SESC - Segurança Alimentar e Nutricional. Banco de Alimentos e Colheita Urbana - 5 critérios de segurança. Disponível em: http://www.ebah.com.br/content/ABAAAAze0AH/criterios-seguranca. Acesso em: 10 out. 2012.

MEYER, S. T. O uso do cloro na desinfecção de águas, a formação de trihalometanos e os riscos potenciais à saúde pública. Caderno Saúde Pública, v. 10, n. 1, p. 99-110, 1994. http://dx.doi.org/10.1590/S0102-311X1994000100011

MINISTRY OF AGRICULTURE, FISHERIES AND FOOD (MAFF), Food Safety: A Guide from the Food Safety Directorate, Food Sense, London, 1991.

NANÔ, F. Número de idosos dobrou nos últimos 20 anos no Brasil, aponta IBGE. Uol Noticias, São Paulo, 21 set. 2012. Cotidiano. Disponível em: <http://noticias.uol.com.br/cotidiano/ultimas-noticias/2012/09/21/numero-de-idososcom-mais-de-60-anos-dobrou-nos-ultimos-20-anos-aponta-ibge.htm>. Acesso em 10 jul. 2012.

NASCIMENTO, A.R.; MOUCHREK FILHO, J.E.; MOUCHREK, V.E.; MARTINS, A.G.A.L.; BAYMA, A.B.; GOMES, S.V.; MARINHO, S.C.; CARVALHO, P.A.B.; GARCIAS JUNIOR, A.V. Incidência de Escherichia coli e Salmonella em alface (Lactuca sativa). Higiene Alimentar, v. 19, n. 128, p. 121-124, 2005.

NICOLLE L. E. Urinary tract infections in geriatric institutionalized patients. Current Opinion in Urology, v. 12, n. 1, p. 51-5, 2002. http://dx.doi.org/10.1097/00042307-200201000-00010

OMS. Organização Mundial de Saúde. Five Keys for Safer Food Manual. 2006.

PALÚ, A.P.; TIBANA, A. TEIXEIRA, L.M.; MIGUEL, M.A.L.; PYRRHO, A.S. LOPES, H.R. Avaliação microbiológica de frutas e hortaliças frescas, servidas em restaurantes privados da Universidade Federal do Rio de Janeiro. Higiene Alimentar, v. 16, n. 100, p. 67-74, 2002.

PAUlA, P.; RODRIGUES, P.S.dos S.; TÓRTORA, J.C. de O.; UCHÔA, C.M.A.; FARAGE, S. Contaminação microbiológica e parasitológica em alfaces (Lactuca sativa) de restaurantes self-service, de Niterói, RJ. Revista da Sociedade Brasileira de Medicina Tropical. Comunicação. v. 36, n. 4, p. 535-537, 2003.

PERETTI, A. P. de R.; ARAÚJO, W. M. C. Abrangência do requisito segurança em certificados de qualidade da cadeia produtiva de alimentos no Brasil. Gestão \& Produção, São Carlos, v. 17, n. 1, p. 35-49, 2010.

PREVOTS D. R.; SUTTER R. W. Assessment of Guillain-Barré syndrome mortality and morbidity in the United States: implications for acute flaccid paralysis surveillance. The Journal of Infectious Diseases, v. 175, suppl.1, p. 151S-5S, 1997. http://dx.doi.org/10.1093/infdis/175.Supplement_1.S151

PUREZA, I. R. O. M.; SOUZA, E. C.; PEREIRA, W. D. Eficiência da desinfecção pelo calor em esponjas de limpeza utilizadas em cozinhas residenciais. Centro Universitário CESMAC. Disponível em: <http://www.adaltech.com.br/sigeventos/conbran2012/inscricao/resumos/0001/R0322-1.PDF>. Acesso em 04 out. 2012.

SANTOS, A. de O.; BIONDI, G.F. Qualidade das hortaliças comercializadas no Distrito Federal. Higiene Alimentar, v. 23, n. 170/171, p. 138-141, 2009. 
SENAC. Série Qualidade e Segurança Alimentar. Guia passo a passo. Implantação de Boas Práticas e Sistema APPCC. Rio de Janeiro: SENAC/DN, 2001. 229p.

SILVA, A. D. L.; CATÃO, M. H. C. V. Doenças sistêmicas em idosos não institucionalizados. HU Revista, Juiz de Fora, v. 37, n. 3, p. 299-303, 2012.

SMITH, J. L. Foodborne illness in the elderly. Journal of Food Protection, v. 61, n. 9, p. 1229-1239(11), 1998.

SOUNIS, E. Manual de Higiene e Medicina do Trabalho, $3^{\text {a }}$ edição, São Paulo, Mc Gram Hill, 1995.

U. S. DEPARTMENT OF AGRICULTURE; FOOD AND DRUG ADMINISTRATION. Food Safety for Older Adults: a need-to-know guide for those 65 years of age and older. September 2006. Slightly revised September 2011.

WORSFOLD, D; GRIFFITH, C. Food safety behaviour in the home. British Food Journal, v. 99, n. 3, p. 97-104, 1997.

XAVIER, R. N. Brasília, 2009. Convivendo com o inimigo - Cozinha domiciliar e riscos de contaminação alimentar. 2009. Monografia (Especialização em Qualidade de Alimentos), Universidade de Brasília.

YAMAYA M.; YNAI M.; OHRUI T.; ARAI H.; SASAKI H. Interventions to prevent pneumonia among older adults. Journal of American Geriatrics Society, v. 49, n. 1, p. 85-90, 2001. http://dx.doi.org/10.1046/j.15325415.2001.49015.x

ZENEBON, O.; MAIO, F. D.; SAKUMA, A. M.; ROSA, E. Determinação de mercúrio em águas sanitárias comercializadas em região do sudeste do Brasil. Revista de Saúde Pública, v. 28, n. 2 , 1994. http://dx.doi.org/10.1590/S0034-89101994000200006

Submetido em 12 mar. 2013; Aceito para publicação em 09 abr. 2014. 